\title{
Impact of overweight and obesity on acute exacerbations of COPD - subgroup analysis of the Taiwan Obstructive Lung Disease cohort
}

This article was published in the following Dove Press journal:

International Journal of COPD

12 September 2017

Number of times this article has been viewed

\author{
Yu-Feng Wei ${ }^{1,2}$ \\ Ying-Huang Tsai ${ }^{3}$ \\ Chin-Chou Wang ${ }^{4}$ \\ Ping-Hung Kuo ${ }^{5}$ \\ On behalf of the TOLD \\ Study Group \\ 'Department of Internal Medicine, \\ E-Da Hospital, I-Shou University, \\ Kaohsiung, ${ }^{2}$ Institute of Biotechnology \\ and Chemical Engineering, I-Shou \\ University, Kaohsiung, ${ }^{3}$ Department \\ of Internal Medicine, Chang Gung \\ Memorial Hospital, Chiayi, ${ }^{4}$ Division \\ of Pulmonary and Critical Care \\ Medicine, Kaohsiung Chang Gung \\ Memorial Hospital and Chang Gung \\ University College of Medicine, \\ Kaohsiung, ${ }^{5}$ Department of Internal \\ Medicine, National Taiwan University \\ Hospital, Taipei, Taiwan, Republic \\ of China
}

Correspondence: Ping-Hung Kuo Department of Internal Medicine, National Taiwan University Hospital, No 7, Chung-Shan South Road, Taipei 100, Taiwan, Republic of China Tel +886 223123456 ext 65445 Fax +886223582867

Email kph712@ntuh.gov.tw
Purpose: A low body mass index (BMI) is a poor prognostic marker of acute exacerbations and mortality in patients with COPD. However, the impact of overweight and obesity on COPD-related outcomes is uncertain. The aim of this study was to examine whether a high $\mathrm{BMI}$ is associated with the frequent exacerbator phenotype ( $\geq 2 /$ year) in Taiwanese patients with COPD.

Patients and methods: Data were obtained from the Taiwan Obstructive Lung Disease study, a retrospective, observational nationwide survey of COPD patients conducted at 12 hospitals in Taiwan. Multivariate logistic regression models were used to explore the association between BMI and other factors with the frequency of COPD exacerbations in these patients.

Results: Among the whole study cohort $(n=1,096), 735$ (67.1\%) had no exacerbations and 148 $(13.5 \%)$ were frequent exacerbators in the previous year. The BMI values of the patients with 0,1 , and $\geq 2$ exacerbations were 23.6, 23.5, and $22.6 \mathrm{~kg} / \mathrm{m}^{2}$, respectively. In all, $256(23.4 \%)$ and 196 (17.9\%) patients were overweight $\left(27 \mathrm{~kg} / \mathrm{m}^{2}>\right.$ BMI $\left.\geq 24 \mathrm{~kg} / \mathrm{m}^{2}\right)$ and obese $\left(B M I \geq 27 \mathrm{~kg} / \mathrm{m}^{2}\right)$, respectively. Even after adjusting for multiple factors, overweight and obesity were associated with the frequency of exacerbations (odds ratio [95\% confidence interval] 0.49 [0.28-0.87, $P=0.015]$ and 0.49 [0.26-0.94, $P=0.033]$, respectively).

Conclusion: Our results suggest that overweight and obesity are associated with a lower frequency of COPD exacerbations in Taiwan.

Keywords: acute exacerbation, COPD, obesity, overweight

\section{Introduction}

COPD is a significant health burden worldwide and, currently, the seventh leading cause of death in Taiwan. ${ }^{1}$ The natural history of COPD is punctuated by exacerbations, defined as acute worsening of symptoms. COPD exacerbations have been shown to be associated with an accelerated decline in pulmonary function, poorer health-related quality of life (HRQL), and higher mortality rate. ${ }^{2}$

Involuntary weight loss is a common complication in COPD, and between $20 \%$ and $70 \%$ of patients with COPD have been reported to be underweight depending on the population studied. ${ }^{3}$ A low body mass index (BMI) and cachexia have been associated with negative outcomes in these patients, independent of the degree of airflow limitation. ${ }^{4-7}$ Lin et $\mathrm{l}^{8}$ reported that a cross-sectional study in Taiwan indicated that lower BMI is associated with osteoporosis in patients with COPD. However, the impact of overweight and obesity on outcomes in patients with COPD remains controversial. Some studies have reported that overweight or obesity had a protective effect against mortality in patients with COPD, ${ }^{6,7,9}$ while others have reported a worse 
HRQL, increased severity of dyspnea and frequency of severe exacerbations in obese patients with COPD. ${ }^{10-12}$ To the best of our knowledge, few studies have explored the relationship between overweight or obesity and the frequency of COPD exacerbations. ${ }^{12-15}$

Therefore, the aim of this study was to examine whether overweight and obesity are associated with the frequency of acute exacerbations in patients with COPD in Taiwan.

\section{Patients and methods}

\section{Study design and patients}

The Taiwan Obstructive Lung Disease (TOLD) study was a retrospective, observational nationwide survey of patients with COPD conducted at 12 hospitals in Taiwan (including seven medical centers and five regional hospitals) from December 2011 through November 2013. All patients enrolled in this survey were $>40$ years of age with a diagnosis of COPD based on the 2011 GOLD guidelines. ${ }^{16}$ The study protocol was reviewed and approved by the individual institutional review board of each center (see 'Acknowledgment' section), and all patients provided informed consent.

\section{Data collection}

Demographic and clinical data related to COPD were collected, including age, gender, smoking history, concomitant diseases, presence of wheezing, grade and severity of pulmonary function, reversibility of bronchodilator test, modified Medical Research Council (mMRC) dyspnea scale, COPD Assessment Test (CAT) score, exacerbation history, and maintenance pharmacological treatment. BMI was calculated as weight in kilograms divided by the square of the height in meters. BMI cutoff values were adopted as suggested by the Department of Health in Taiwan, including normal $\left(18.5 \mathrm{~kg} / \mathrm{m}^{2} \leq \mathrm{BMI}<24 \mathrm{~kg} / \mathrm{m}^{2}\right)$, overweight $\left(24 \mathrm{~kg} / \mathrm{m}^{2} \leq\right.$ BMI $\left.<27 \mathrm{~kg} / \mathrm{m}^{2}\right)$, and obese (BMI $\geq 27 \mathrm{~kg} / \mathrm{m}^{2}$ ) categories. ${ }^{17}$ A wheezing phenotype was defined as the documentation of two or more episodes of wheezing in the medical records during the past 1 year at the time of enrollment. An exacerbation was defined as the prescription of a short course of antibiotics and/or oral steroids or an emergency department visit/hospitalization due to an acute respiratory episode recorded in the medical records during the previous 1 year. A frequent exacerbator phenotype was defined as two or more exacerbations in 1 year. $^{2}$ Spirometry within 6 months at enrollment was acceptable for record. Reversibility in the bronchodilator test was defined as an increase of $12 \%$ and $200 \mathrm{~mL}$ in forced vital capacity (FVC) or forced expiratory volume in the first second $\left(\mathrm{FEV}_{1}\right)$.

\section{Statistical analysis}

Continuous parameters were presented as mean $\pm \mathrm{SD}$, and categorical parameters were presented as number and percentage. Statistical differences in clinical features between the patients with a BMI $<24 \mathrm{~kg} / \mathrm{m}^{2}$ and those with a BMI $\geq 24 \mathrm{~kg} / \mathrm{m}^{2}$ were determined using the chi-square test and Yates correction or Fisher's exact test for categorical variables and the Student's $t$-test for continuous variables where appropriate. The Wilcoxon rank-sum test was used if normal assumption was violated. One-way analysis of variance (ANOVA) or Kruskal-Wallis test was performed for analysis of more than two groups as appropriate. Multivariate logistic regression models were used to clarify the predictors of the frequent exacerbator phenotype ( $\geq 2$ times/ year) in the patients with COPD. All tests of significance were two sided, and a $P$-value of $<0.05$ was considered to be statistically significant. All analyses were performed using SPSS 22.0 software (IBM Corporation, Armonk, NY, USA) for Windows.

\section{Results}

A total of 1,096 patients with COPD were included in the original TOLD study, and their demographic characteristics are summarized in Table 1. Of these patients, 9.2\%, 49.5\%, $23.4 \%$, and $17.9 \%$ were underweight, normal, overweight, and obese, respectively. The overweight and obese patients $(n=452)$ accounted for $41.2 \%$ of all patients.

Figure 1 shows the patients with few ( $0-1$ time/year) exacerbations had a significantly higher BMI than those with the frequent exacerbator phenotype ( $P=0.019)$. In addition, the patients with a $B M I \geq 24$ had fewer COPD exacerbations than those with a $\mathrm{BMI}<24$, and the lowest rate of exacerbations was observed in the overweight patients, but the differences were not statistically significant (Figure 2). The patients with a higher BMI had a significantly higher rate of comorbidities (Table 2), of which cardiovascular disease, hypertension, diabetes mellitus, ischemic heart disease, and dyslipidemia were the most common.

The results of multivariate logistic regression analysis for the frequent exacerbator phenotype are summarized in Table 3. The wheezing phenotype and a higher mMRC score were positively associated with the frequent exacerbator phenotype, with odds ratios (ORs) of 4.52 (95\% confidence interval $[\mathrm{CI}] 2.84-7.20, P<0.001)$ and 1.36 (95\% CI 1.07-1.73, $P=0.011)$, respectively. In contrast, the overweight and obese patients were inversely related to the frequent exacerbator phenotype (OR 0.49 [95\% CI 0.28-0.87], $P=0.015$, and 0.49 [95\% CI 0.26-0.94], $P=0.033$, respectively). 
Table I Demographic characteristics of the study population by BMI category $(n=I, 096)$

\begin{tabular}{|c|c|c|c|c|c|c|c|c|}
\hline \multirow[t]{2}{*}{ Characteristics } & \multicolumn{8}{|c|}{ BMI $\left(\mathrm{kg} / \mathrm{m}^{2}\right)$} \\
\hline & $<\mathbf{1 8 . 5}$ & $18.5-23.9$ & $24-26.9$ & $\geqq 27$ & $P$-value & $<23.9$ & $\geqq 24$ & $P$-value \\
\hline Patient number, n (\%) & I0I (9.2) & $543(49.5)$ & $256(23.4)$ & $196(17.9)$ & & $644(58.8)$ & $452(4 \mid .2)$ & \\
\hline Male gender, $\mathrm{n}(\%)$ & $93(92.1)$ & $515(94.8)$ & $244(95.3)$ & $181(92.3)$ & 0.380 & $608(94.4)$ & $625(94.0)$ & 0.788 \\
\hline Smoking history, n (\%) & & & & & 0.249 & & & 0.081 \\
\hline Never & $10(10.2)$ & $47(9.0)$ & $25(10.1)$ & $23(12.0)$ & & $57(9.2)$ & $48(10.9)$ & \\
\hline Ex-smoker & $52(53.1)$ & $292(55.7)$ & $157(63.3)$ & $107(55.7)$ & & $344(55.3)$ & $264(60.0)$ & \\
\hline Currently smoking & $36(36.7)$ & $185(35.3)$ & $66(26.6)$ & $62(32.3)$ & & $211(35.5)$ & $128(29.1)$ & \\
\hline 2006 GOLD criteria classification, n (\%) & & & & & $<0.001$ & & & $<0.001$ \\
\hline Stage I & $15(14.9)$ & $89(16.4)$ & $53(20.7)$ & $34(17.3)$ & & $104(16.1)$ & $87(19.2)$ & \\
\hline Stage 2 & $22(21.8)$ & $221(40.7)$ & $113(44.1)$ & $103(52.6)$ & & $243(37.7)$ & $216(47.8)$ & \\
\hline Stage 3 & $4 \mid(40.6)$ & $168(30.9)$ & $67(26.2)$ & $48(24.5)$ & & $209(32.5)$ & II $5(25.4)$ & \\
\hline Stage 4 & $23(22.8)$ & $65(12.0)$ & $23(9.0)$ & II (5.6) & & $88(13.7)$ & $34(7.5)$ & \\
\hline 20I I GOLD criteria classification, n (\%) & & & & & $<0.001$ & & & $<0.001$ \\
\hline Group A & $5(5.0)$ & $87(16.0)$ & $50(19.5)$ & $37(18.9)$ & & $92(14.3)$ & $87(19.2)$ & \\
\hline Group B & $26(25.7)$ & $184(33.9)$ & $102(39.8)$ & $86(43.9)$ & & $210(32.6)$ & $188(4 \mid .6)$ & \\
\hline Group C & II (I0.9) & $49(9.0)$ & $29(11.3)$ & $10(5.1)$ & & $60(9.3)$ & $39(8.6)$ & \\
\hline Group D & $59(58.4)$ & $223(4 I .1)$ & $75(29.3)$ & $63(32.1)$ & & $282(43.8)$ & $138(30.5)$ & \\
\hline CAT score & & & & & 0.252 & & & 0.172 \\
\hline Number & 101 & 542 & 255 & 196 & & 643 & 451 & \\
\hline Mean \pm SD & $12.6 \pm 8.0$ & II $.4 \pm 7.4$ & $10.5 \pm 6.4$ & II.I \pm 7.0 & & $11.6 \pm 7.5$ & $10.8 \pm 6.7$ & \\
\hline CAT category, n (\%) & & & & & 0.267 & & & 0.222 \\
\hline$\geqq 10$ & $61(60.4)$ & $291(53.7)$ & $125(49.0)$ & $105(54.7)$ & & $352(48.2)$ & $230(51.0)$ & \\
\hline$<10$ & $40(39.6)$ & $25 I(46.3)$ & $130(51.0)$ & 91 (46.4) & & $291(45.3)$ & $22 I(49.0)$ & \\
\hline mMRC score & & & & & 0.024 & & & 0.055 \\
\hline Number & 93 & 484 & 232 & 163 & & 577 & 395 & \\
\hline Mean \pm SD & $2.1 \pm 1.0$ & $1.8 \pm 0.9$ & $1.7 \pm 1.0$ & $1.8 \pm 0.8$ & & $1.9 \pm 0.9$ & $1.8 \pm 1.0$ & \\
\hline mMRC category, n (\%) & & & & & 0.034 & & & 0.045 \\
\hline$\geqq 2$ & $68(73.1)$ & $306(63.2)$ & $130(56.0)$ & $\mathrm{IOI}(62.0)$ & & $374(64.8)$ & $231(58.5)$ & \\
\hline $0-1$ & $25(26.9)$ & $178(36.8)$ & $102(44.0)$ & $62(38.0)$ & & $203(35.2)$ & $164(4 \mid .5)$ & \\
\hline Wheezing phenotype, n (\%) & & & & & 0.055 & & & 0.214 \\
\hline Yes & $30(29.7)$ & $229(42.2)$ & 97 (37.9) & $68(34.7)$ & & $259(40.2)$ & $165(36.5)$ & \\
\hline No & $71(70.3)$ & $314(57.8)$ & $159(62.1)$ & $128(65.3)$ & & $385(59.8)$ & $287(63.5)$ & \\
\hline Bronchodilator responder, n (\%) & & & & & 0.021 & & & 0.214 \\
\hline Yes & $0(0.0)$ & $34(7.2)$ & $22(10.0)$ & $10(5.8)$ & & $34(6.1)$ & $32(8.2)$ & \\
\hline No & $82(100.0)$ & $440(92.8)$ & $197(90.0)$ & I6I (94.2) & & $522(93.9)$ & $358(9 \mid .8)$ & \\
\hline No of AEs within the past I year, $n(\%)$ & & & & & 0.179 & & & 0.015 \\
\hline 0 & $64(63.4)$ & $353(65.0)$ & $183(7 \mid .5)$ & 135 (68.9) & & $417(64.8)$ & $318(70.4)$ & \\
\hline I & $20(19.8)$ & $104(19.2)$ & $49(19.1)$ & $40(20.4)$ & & $124(19.3)$ & $89(19.7)$ & \\
\hline$\geqq 2$ & $17(16.8)$ & $86(15.8)$ & $24(9.4)$ & $21(10.7)$ & & $103(16.0)$ & $45(10.0)$ & \\
\hline
\end{tabular}

Note: Bronchodilator responder was defined as an increase of $12 \%$ and $200 \mathrm{~mL}$ in the $\mathrm{FEV}$, or FVC after bronchodilator drug treatment.

Abbreviations: AE, acute exacerbation; BMI, body mass index; CAT, COPD Assessment Test; GOLD, Global Initiative for Chronic Obstructive Lung Disease; mMRC modified Medical Research Council; SD, standard deviation.

\section{Discussion}

In this study, we retrospectively investigated the relationship between BMI and the frequency of COPD exacerbations in Taiwan. We found that overweight and obese patients with COPD were not uncommon in Taiwan and that these patients were associated with a lower frequent exacerbator phenotype. Moreover, the wheezing phenotype and a higher mMRC score were also related to this phenotype. These findings indicate that a high BMI is a predictor for a better outcome in terms of acute exacerbations in patients with COPD.
The prediction and prevention of COPD exacerbations are important goals in the management of COPD. BMI is an easily accessible parameter for patient assessment and risk stratification. It is well known that underweight increases the risk of mortality in patients with COPD. However, the impact of increased body weight on the outcomes of COPD was not conclusive. Cao et al ${ }^{7}$ conducted a meta-analysis of 22 studies with 21,150 participants and concluded that overweight and obese COPD patients were associated with a lower risk of mortality (risk ratio [RR] $0.47,95 \%$ CI $0.33-0.68$, and 


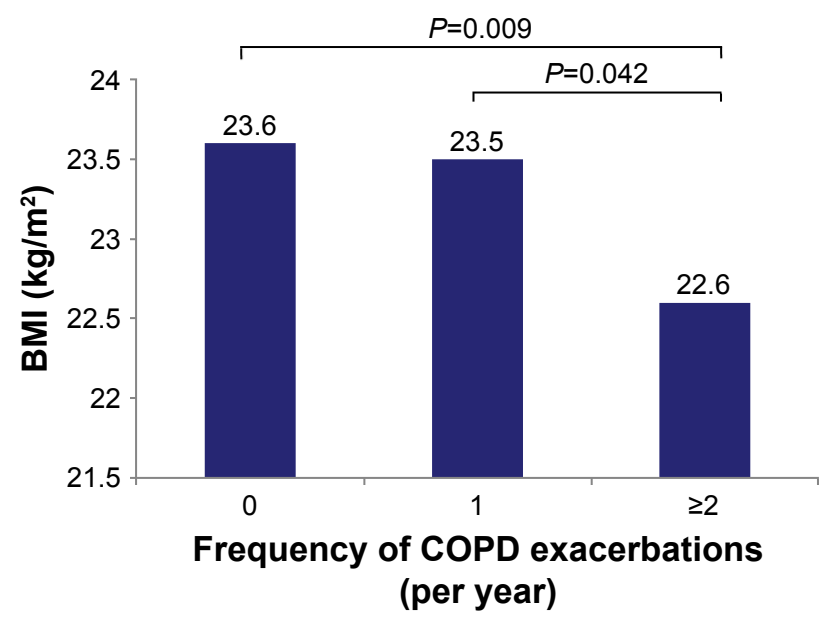

Figure I Frequency of COPD exacerbations in the previous year (overall, $P=0.019$ ). Abbreviation: BMI, body mass index.

RR 0.59, 95\% CI 0.38-0.91, respectively) than those with a normal BMI. On the other hand, a multicenter prospective cohort study conducted by Lambert et $\mathrm{al}^{12}$ found that obesity was associated with worse COPD-related outcomes, including HRQL, dyspnea (mMRC score) during a 6-minute walk test, and severe exacerbations of COPD.

The results of our study are similar to a cross-sectional study reported by Cecere et al, ${ }^{18}$ which showed a trend toward a lower frequency of COPD exacerbations in overweight or obese patients compared to normal-weight patients. Another study conducted by Jacob et $\mathrm{al}^{14}$ also showed a lower incidence of hospitalized patient-treated exacerbations in overweight COPD patients. Other studies, however, have reported different results, such as the study of Lambert et al that reported that obesity was associated with severe exacerbations of COPD. ${ }^{12}$ The possible explanations for the contradictory results may include differences in ethnicity, obesity levels, comorbidities,

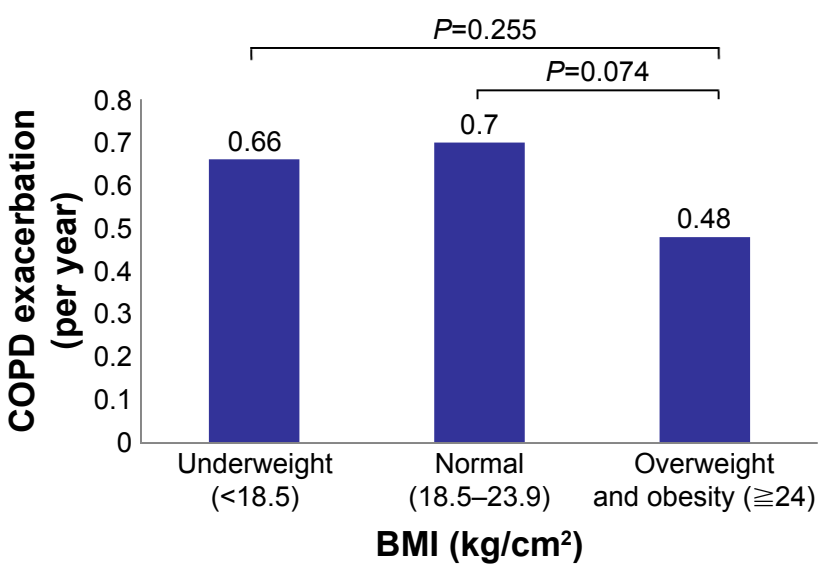

Figure 2 Frequency of COPD exacerbations by BMI category (overall, $P=0.062$ ). Abbreviation: BMI, body mass index. and exacerbation types. Ethnic differences may affect the role of obesity due to body fat distribution. ${ }^{19}$ In addition, the current study compared overweight/obese patients to normal-weight patients, rather than obese patients to normal/ overweight patients in Lambert et al's study. Furthermore, different cutoff points of obese level may have interfered with the outcomes in these studies. Finally, obesity was only associated with severe but not moderate exacerbations in Lambert et al's study. However, we did not have data on the severity of the exacerbations. A large prospective cohort study conducted by Colak et $\mathrm{al}^{15}$ showed that only genetically determined, but not observationally determined, high BMI was associated with an increased risk of recurrent exacerbations and pneumonias in individuals with COPD.

The mechanisms underlying the protection of a higher BMI against COPD exacerbations in this study are unclear. Overweight and obesity have been linked to a better prognosis in patients suffering from various chronic diseases, especially cardiovascular disease, which has been termed the obesity paradox. ${ }^{20-23}$ The mechanism responsible for this phenomenon is still unclear. ${ }^{24}$ Circulating adipokines such as leptin and adiponectin may regulate metabolic and inflammatory systems, which play important roles in obese patients. ${ }^{25}$ It is well known that most obese individuals have higher levels of serum leptin and lower levels of serum adiponectin compared to non-obese individuals, indicating chronic inflammation in obese patients. ${ }^{26}$ Krommidas et $\mathrm{al}^{27}$ reported a higher leptin/adiponectin ratio during COPD exacerbations and a lower ratio during the resolution period. However, the significance of the association between adipokines and COPD is still controversial. Wolk et $\mathrm{al}^{28}$ reported that patients with a low BMI with a high leptin/adiponectin ratio and patients with a high BMI with a low leptin/adiponectin ratio were associated with better cardiovascular outcomes, indicating the complexity of the underlying pathophysiology. In addition, cardiorespiratory fitness and physical activity may also have positive effects on reducing deconditioning and play an important role in the obesity paradox. ${ }^{29}$ In addition, the effects of overweight and obesity on exacerbations may be different in patients with asthma and COPD. A multicenter study of patients presented to the emergency department with asthma exacerbation showed that obese adults were at a higher risk of hospitalization compared with normal-weight adults. ${ }^{30}$ This may reflect a difference in the perception of dyspnea, or it may reflect an underlying difference in asthma severity between the two groups. In a recent study by Denlinger et al, ${ }^{31}$ patients with exacerbation-prone asthma ( $>3 /$ year) had a higher BMI than patients with few or no exacerbations. 
Table 2 Comorbidities of the study participants

\begin{tabular}{|c|c|c|c|c|c|c|c|c|}
\hline \multirow[t]{2}{*}{ Characteristics } & \multicolumn{4}{|c|}{ BMI $\left(\mathbf{k g} / \mathbf{m}^{2}\right)$} & \multirow[t]{2}{*}{$P$-value } & \multicolumn{2}{|c|}{ BMI $\left(\mathbf{k g} / \mathbf{m}^{2}\right)$} & \multirow[t]{2}{*}{$P$-value } \\
\hline & $\begin{array}{l}<18.5 \\
(n=101)\end{array}$ & $\begin{array}{l}18.5-23.9 \\
(n=543)\end{array}$ & $\begin{array}{l}24-26.9 \\
(n=256)\end{array}$ & $\begin{array}{l}\geqq 27 \\
(n=196)\end{array}$ & & $\begin{array}{l}<23.9 \\
(n=644)\end{array}$ & $\begin{array}{l}\geqq 24 \\
(n=452)\end{array}$ & \\
\hline \multicolumn{9}{|l|}{ Comorbidity, n (\%) } \\
\hline Cardiovascular disease & $33(32.7)$ & $229(42.2)$ & I4I (55.I) & $120(6 \mid .2)$ & $<0.001$ & $262(40.7)$ & $261(57.7)$ & $<0.001$ \\
\hline Hypertension & $21(20.8)$ & $184(33.9)$ & II $3(44.1)$ & $99(50.5)$ & $<0.001$ & $205(31.8)$ & $212(46.9)$ & $<0.001$ \\
\hline Diabetes mellitus & $9(8.9)$ & $71(13.1)$ & $42(16.4)$ & $44(22.4)$ & 0.004 & $80(12.4)$ & $86(19.0)$ & 0.003 \\
\hline Ischemic heart disease & $8(7.9)$ & $43(7.9)$ & $33(12.9)$ & $27(13.8)$ & 0.037 & $51(7.9)$ & $60(13.3)$ & 0.004 \\
\hline Dyslipidemia & I (I.0) & $31(5.7)$ & $20(7.8)$ & $26(13.3)$ & $<0.001$ & $32(5.0)$ & $46(10.2)$ & $<0.001$ \\
\hline Congestive heart failure & $4(4.0)$ & $25(4.6)$ & $21(8.2)$ & $14(7.1)$ & 0.147 & $29(4.5)$ & $35(7.7)$ & 0.024 \\
\hline Arrhythmia & $3(3.0)$ & $18(3.3)$ & II (4.3) & $14(7.1)$ & 0.129 & $21(3.3)$ & $25(5.5)$ & 0.065 \\
\hline Lung cancer & $I(1.0)$ & $15(2.8)$ & $2(0.8)$ & $5(2.6)$ & 0.248 & $16(2.5)$ & $7(1.5)$ & 0.287 \\
\hline Other malignancies & $3(3.0)$ & $19(3.5)$ & $10(3.9)$ & $6(3.1)$ & 0.956 & $22(3.4)$ & $16(3.5)$ & 0.912 \\
\hline Osteoporosis & $4(4.0)$ & $13(2.4)$ & $7(2.7)$ & $5(2.6)$ & 0.843 & $17(2.6)$ & $12(2.7)$ & 0.988 \\
\hline Anxiety & $2(2.0)$ & $10(1.8)$ & $6(2.3)$ & $4(2.0)$ & 0.974 & $12(1.9)$ & $10(2.2)$ & 0.685 \\
\hline Depression & I (I.0) & $10(1.8)$ & $4(1.6)$ & $5(2.6)$ & 0.785 & $11(1.7)$ & $9(2.0)$ & 0.730 \\
\hline
\end{tabular}

Abbreviation: $\mathrm{BMI}$, body mass index.

There are several limitations to this study. First, the data were collected retrospectively, and only 12 hospitals in Taiwan were involved in the recruitment of patients in the TOLD cohort, which may lead to selection bias. However, the selection of the study sites (including medical centers and regional hospitals) and good geographic representation

Table 3 Multivariate logistic regression analysis of the frequent exacerbator phenotype ( $A E \geqq 2 /$ year)

\begin{tabular}{|c|c|c|c|}
\hline \multirow[t]{2}{*}{ Characteristics } & \multicolumn{3}{|c|}{ Multivariate } \\
\hline & OR & $95 \% \mathrm{Cl}$ & $P$-value \\
\hline \multicolumn{4}{|l|}{ BMI $\left(\mathrm{kg} / \mathrm{m}^{2}\right)$} \\
\hline$<18.5$ & 1.21 & $0.61,2.39$ & 0.584 \\
\hline $18.5-23.9$ & Reference & - & - \\
\hline $24-26.9$ & 0.49 & $0.28,0.87$ & 0.015 \\
\hline$\geqq 27$ & 0.49 & $0.26,0.94$ & 0.033 \\
\hline Age & 0.99 & $0.96,1.01$ & 0.232 \\
\hline Male gender & 1.07 & $0.38,3.02$ & 0.895 \\
\hline \multicolumn{4}{|l|}{ Smoking history } \\
\hline $\begin{array}{l}\text { Ex-smoker versus never } \\
\text { smoker }\end{array}$ & 1.21 & $0.53,2.74$ & 0.652 \\
\hline $\begin{array}{l}\text { Current smoker versus } \\
\text { never smoker }\end{array}$ & 0.69 & $0.29,1.66$ & 0.409 \\
\hline Previous medication & 1.63 & $0.62,4.28$ & 0.319 \\
\hline Wheezing phenotype & 4.52 & $2.84,7.2$ & $<0.00$ I \\
\hline CAT score $\geqq 10$ & 1.02 & $0.99,1.05$ & 0.203 \\
\hline $\mathrm{mMRC}$ score $\geqq 2$ & 1.36 & $1.07,1.73$ & 0.011 \\
\hline \multicolumn{4}{|l|}{ Comorbidities } \\
\hline Cardiovascular disease & 1.88 & $0.84,4.23$ & 0.126 \\
\hline Ischemic heart disease & 0.87 & $0.41,1.86$ & 0.714 \\
\hline Hypertension & 0.80 & $0.37,1.72$ & 0.562 \\
\hline Diabetes & 1.28 & $0.74,2.23$ & 0.381 \\
\hline Dyslipidemia & 0.82 & $0.36,1.85$ & 0.626 \\
\hline
\end{tabular}

Abbreviations: AE, acute exacerbation; BMI, body mass index; CAT, COPD Assessment Test; Cl, confidence interval; mMRC, modified Medical Research Council; OR, odds ratio. minimized this limitation. Second, a relatively small number of subjects with extreme and morbid obesity in the study population were involved, which may preclude the generalization of our findings to these patients. Third, BMI was used as a sole measurement of obesity in this study. The type of obesity and fat distribution, as well as the amount of visceral fat, were not assessed. Further prospective study is necessary to clarify various anthropometric parameters and their clinical relevance in COPD patients.

\section{Conclusion}

Our findings suggest that a higher BMI is a predictor of a better outcome in terms of acute exacerbations in Taiwanese patients with COPD. The lowest frequency of COPD exacerbations was observed in the overweight patients. These findings cannot be extended to patients with extreme or morbid obesity because of the small number of such patients included in this study cohort.

\section{Acknowledgments}

The TOLD study received financial support from Novartis Pharmaceuticals Corporation. Data management and statistical analysis were supported by the CRO service division of Formosa Biomedical Technology Corporation. The principal investigators of the TOLD study group included Ming-Shian Lin (Division of Pulmonary and Critical Care Medicine, Chia-Yi Christian Hospital, Chiayi, Taiwan), Shih-Lung Cheng (Division of Thoracic Medicine, Department of Internal Medicine, Far Eastern Memorial Hospital, Taipei, Taiwan and Department of Chemical Engineering and Materials Science, Yuan-Ze University, Taoyuan, 
Taiwan), Wu-Huei Hsu (Division of Pulmonary and Critical Care Medicine, Department of Internal Medicine, China Medical University and China Medical University Hospital, Taichung, Taiwan), Yao-Kuang Wu (Division of Pulmonary Medicine, Department of Internal Medicine, Taipei Tzu Chi Hospital, Taipei, Taiwan), Ning-Hung Chen (Department of Pulmonary and Critical Care Medicine, Chang Gung Memorial Hospital, Linkou, Taiwan), Chao-Hsien Lee (Division of Pulmonary and Critical Care Medicine, Mackay Memorial Hospital, Taipei, Taiwan), Jeng-Yuan Hsu (Division of Chest Medicine, Taichung Veterans General Hospital, Taichung, Taiwan), and Chi-Wei Tao (Department of Internal Medicine, Cheng-Hsin General Hospital, Taipei, Taiwan).

\section{Disclosure}

The authors report no conflicts of interest in this work.

\section{References}

1. Hsiao AJ, Chen LH, Lu TH. Ten leading causes of death in Taiwan: a comparison of two grouping lists. J Formos Med Assoc. 2014;114(8): 679-680.

2. Wedzicha JA, Brill SE, Allinson JP, Donaldson GC. Mechanisms and impact of the frequent exacerbator phenotype in chronic obstructive pulmonary disease. BMC Med. 2013;11:181.

3. Yeh SS, DeGuzman B, Kramer T, Group MS. Reversal of COPDassociated weight loss using the anabolic agent oxandrolone. Chest. 2002;122(2):421-428.

4. Le-Bert G, Santana O, Pineda AM, Zamora C, Lamas GA, Lamelas J. The obesity paradox in elderly obese patients undergoing coronary artery bypass surgery. Interact Cardiovasc Thorac Surg. 2011;13(2): 124-127.

5. Singanayagam A, Schembri S, Chalmers JD. Predictors of mortality in hospitalized adults with acute exacerbation of chronic obstructive pulmonary disease. Ann Am Thorac Soc. 2013;10(2):81-89.

6. Lainscak M, von Haehling S, Doehner W, et al. Body mass index and prognosis in patients hospitalized with acute exacerbation of chronic obstructive pulmonary disease. J Cachexia Sarcopenia Muscle. 2011; 2(2):81-86.

7. Cao C, Wang R, Wang J, Bunjhoo H, Xu Y, Xiong W. Body mass index and mortality in chronic obstructive pulmonary disease: a meta-analysis. PLoS One. 2012;7(8):e43892.

8. Lin CW, Chen YY, Chen YJ, Liang CY, Lin MS, Chen W. Prevalence, risk factors, and health-related quality of life of osteoporosis in patients with COPD at a community hospital in Taiwan. Int J Chron Obstruct Pulmon Dis. 2015;10:1493-1500.

9. Lavie CJ, Milani RV, Ventura HO. Obesity and the "obesity paradox" in cardiovascular diseases. Clin Pharmacol Ther. 2011;90(1):23-25.

10. Badheka AO, Rathod A, Kizilbash MA, et al. Influence of obesity on outcomes in atrial fibrillation: yet another obesity paradox. Am J Med. 2010;123(7):646-651.

11. Liu Y, Pleasants RA, Croft JB, et al. Body mass index, respiratory conditions, asthma, and chronic obstructive pulmonary disease. Respir Med. 2015;109(7):851-859.

12. Lambert AA, Putcha N, Drummond MB, et al; COPDGene Investigators. Obesity is associated with increased morbidity in moderate to severe COPD. Chest. 2017;151(1):68-77.
13. Tsai CL, Camargo CA Jr. The role of body mass index in acute exacerbations of chronic obstructive pulmonary disease. Emerg Med J. 2009; 26(10):701-705.

14. Jacob A, Laurin C, Lavoie KL, et al. The impact of body mass index on inpatient- versus outpatient-treated chronic obstructive pulmonary disease exacerbations. Can Respir J. 2013;20(4):237-242.

15. Colak Y, Afzal S, Lange P, Nordestgaard BG. High body mass index and risk of exacerbations and pneumonias in individuals with chronic obstructive pulmonary disease: observational and genetic risk estimates from the Copenhagen General Population Study. Int J Epidemiol. 2016;45(5):1551-1559.

16. Vestbo J, Hurd SS, Agusti AG, et al. Global strategy for the diagnosis, management, and prevention of chronic obstructive pulmonary disease: GOLD executive summary. Am J Respir Crit Care Med. 2013; 187(4):347-365.

17. Chu NF. Prevalence of obesity in Taiwan. Obes Rev. 2005;6(4): 271-274.

18. Cecere LM, Littman AJ, Slatore CG, et al. Obesity and COPD: associated symptoms, health-related quality of life, and medication use. COPD. 2011;8(4):275-284.

19. Carroll JF, Chiapa AL, Rodriquez M, et al. Visceral fat, waist circumference, and BMI: impact of race/ethnicity. Obesity (Silver Spring). 2008; 16(3):600-607.

20. Lavie CJ, Milani RV, Ventura HO. Obesity and cardiovascular disease: risk factor, paradox, and impact of weight loss. J Am Coll Cardiol. 2009; 53(21):1925-1932.

21. Carnethon MR, De Chavez PJ, Biggs ML, et al. Association of weight status with mortality in adults with incident diabetes. JAMA. 2012; 308(6):581-590.

22. Uretsky S, Messerli FH, Bangalore S, et al. Obesity paradox in patients with hypertension and coronary artery disease. Am J Med. 2007;120(10): 863-870.

23. Flegal KM, Kit BK, Orpana H, Graubard BI. Association of all-cause mortality with overweight and obesity using standard body mass index categories: a systematic review and meta-analysis. JAMA. 2013;309(1): $71-82$.

24. Cravo J, Esquinas AM. Obesity and COPD exacerbations - it's not that simple. Respir Med. 2016;125:103.

25. Greenberg AS, Obin MS. Obesity and the role of adipose tissue in inflammation and metabolism. Am J Clin Nutr. 2006;83(2):461S-465S.

26. Sood A. Obesity, adipokines, and lung disease. J Appl Physiol (1985). 2010;108(3):744-753.

27. Krommidas G, Kostikas K, Papatheodorou G, et al. Plasma leptin and adiponectin in COPD exacerbations: associations with inflammatory biomarkers. Respir Med. 2010;104(1):40-46.

28. Wolk R, Bertolet M, Singh P, et al; BARI 2D Study Group. Prognostic value of adipokines in predicting cardiovascular outcome: explaining the obesity paradox. Mayo Clin Proc. 2016;91(7):858-866.

29. Chittal P, Babu AS, Lavie CJ. Obesity paradox: does fat alter outcomes in chronic obstructive pulmonary disease? COPD. 2015;12(1):14-18.

30. Hasegawa K, Tsugawa Y, Lopez BL, Smithline HA, Sullivan AF, Camargo CA Jr. Body mass index and risk of hospitalization among adults presenting with asthma exacerbation to the emergency department. Ann Am Thorac Soc. 2014;11(9):1439-1444.

31. Denlinger LC, Phillips BR, Ramratnam S, et al; National Heart, Lung, and Blood Institute's Severe Asthma Research Program-3 Investigators. Inflammatory and comorbid features of patients with severe asthma and frequent exacerbations. Am J Respir Crit Care Med. 2017;195(3): 302-313. 
International Journal of COPD

\section{Publish your work in this journal}

The International Journal of COPD is an international, peer-reviewed journal of therapeutics and pharmacology focusing on concise rapid reporting of clinical studies and reviews in COPD. Special focus is given to the pathophysiological processes underlying the disease, intervention programs, patient focused education, and self management protocols.

This journal is indexed on PubMed Central, MedLine and CAS. The manuscript management system is completely online and includes a very quick and fair peer-review system, which is all easy to use. Visit http://www.dovepress.com/testimonials.php to read real quotes from published authors 